\title{
A Theory of Social Impact Bonds
}

\author{
By
}

Daniel L. Tortorice, David E. Bloom, Paige Kirby and John Regan

\author{
June 2020
}

\section{COLLEGE OF THE HOLY CROSS, DEPARTMENT OF ECONOMICS FACULTY RESEARCH SERIES, PAPER NO. 20-01*}

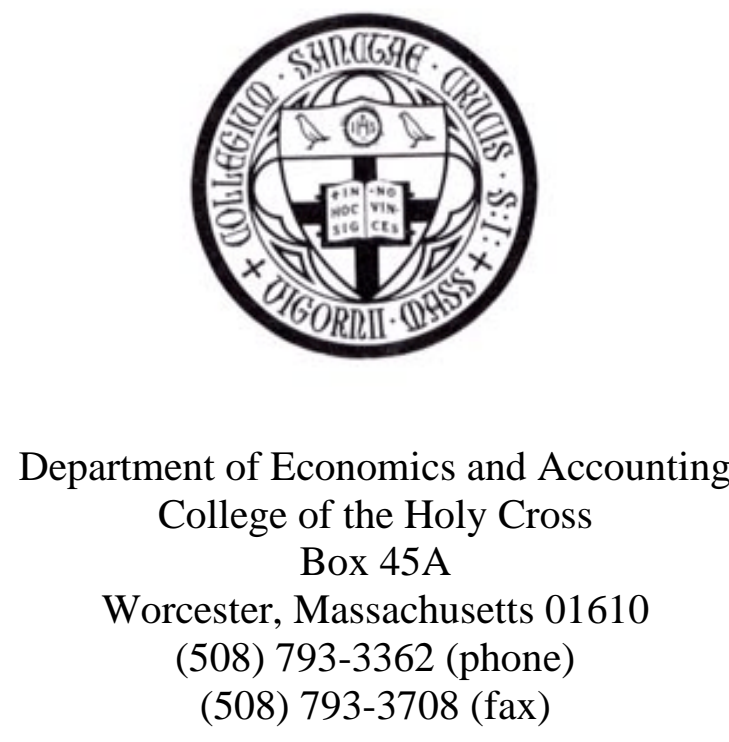

https://www.holycross.edu/academics/programs/economics-and-accounting

*All papers in the Holy Cross Working Paper Series should be considered draft versions subject to future revision. Comments and suggestions are welcome. 


\title{
A Theory of Social Impact Bonds*
}

\author{
Daniel L. Tortoriceł David E. Bloom; Paige Kirby§, and John Regan
}

June 6,2020

\begin{abstract}
Social impact bonds (SIBs) are an innovative financing mechanism for public goods. In a SIB, an investor provides capital to a service provider for a social intervention. The investor receives a return based on the outcome of the intervention relative to a predetermined benchmark. We describe the basic structure of a SIB and provide some descriptive statistics for these financial instruments. We then consider a formal model of SIBs and examine their ability to finance positive net present value projects that traditional debt finance cannot. We find that SIBs expand the set of implementable projects if governments are pessimistic (relative to the private sector) about the probability an intervention would succeed or if the government is particularly averse to paying costs associated with a project that does not generate offsetting benefits. As both these features are present in various public programs, we conclude that SIBs are a real innovation in public finance and should be considered for projects when traditional debt finance has been rejected.
\end{abstract}

JEL Codes: G12, H41

Keywords: Fixed Income Securities, Public Services, Impact Investing, Social Impact Bonds

${ }^{*}$ We thank Lindsey Bennett for excellent research assistance. We thank Raymond Farkouh, Joseph Kelly, Sarah Pugh, and James Wassil for helpful discussions. Dan Tortorice thanks the Robert L. Ardizzone ('63) Fund for tenure track faculty excellence for research support. This paper is based in part on earlier research funded by Pfizer, Inc.

${ }^{\dagger}$ Department of Economics and Accounting, College of the Holy Cross and Data for Decisions, LLC. 1 College St. Worcester MA 01610, dtortori@holycross.edu

†Department of Global Health and Population, Harvard TH Chan School of Public Health and Data for Decisions, LLC. 665 Huntington Avenue, Building I 12th Floor, Suite 1202, Boston, MA 02115, USA, dbloom@hsph.harvard.edu

${ }^{\S}$ Senior Research Associate, Data for Decisions, LLC., 681 Main St \#3, Waltham, MA 02451, pkirby@datafordecisions.net

"Senior Research Associate, Data for Decisions, LLC., 681 Main St \#3, Waltham, MA 02451, jregan@datafordecisions.net 


\section{Introduction}

Impact investing, financial investing that values positive social or environmental impact and traditional financial returns, is a growing field in asset management. ${ }^{1}$ In 2018 , professionals who considered environmental and social factors in their investment choices managed (USD) 12 trillion dollars of assets, representing a $38 \%$ increase over the previous two years (Aitken et al., 2018). One type of impact investing is the social impact bond (SIB), an arrangement where investors in a project receive financial returns based on the project outcomes, specifically the accomplishment of prespecified social objectives.

In a traditional social impact bond, a government attracts financing from an investor. The investor passes the financing on to a service provider who implements a project designed to solve a specific social problem. If the project meets specified social goals, e.g., test scores for an education intervention, the investor receives the initial investment back plus interest payments. In many of these arrangements, investors do not receive any money back if the goals are not met. For payments to be made, a third-party assessor must certify that the intervention achieved the prespecified goals. Given the complexity of these arrangements, an additional entity, known as the intermediary, often co-ordinates the various parties to the SIB arrangement. ${ }^{2}$

Social impact bonds have been growing since their initial launch in September of 2010. For example, 2017 saw the launch of 41 unique SIBs. Currently 81 SIB projects are ongoing with a total of (USD) 375 million invested. ${ }^{3}$

Despite the growth of social impact bonds as a vehicle for financing public programs, with the exception of Pauly and Swanson (2017), we have been unable to find a theoretical analysis of the benefits of SIBs. Our paper address this disparity. Specifically, within the context of an economic model, we compare SIBs to debt finance and characterize the conditions under

\footnotetext{
${ }^{1}$ For academic work on impact investing see Bialkowski and Starks (2016) or the survey of Renneboog et al. (2008).

${ }^{2}$ Many reports describe the structure of SIBs. For one example, see Gustafsson-Wright et al. (2015).

${ }^{3}$ Statistics are authors' calculations based on data from the Social Finance Impact Bond Global Database, https://sibdatabase.socialfinance.org.uk/. See Social Finance (2019).
} 
which SIBs can expand the set of projects that a government can finance.

We find that social impact bonds have advantages over traditional debt finance. Specifically, when the government is unduly pessimistic or particularly averse to states of the world when project costs cannot be offset with project benefits, then SIBs can finance positive net present value projects that debt finance cannot. We conclude that SIBs are a useful form of finance and should be considered for projects when debt finance has been rejected.

The intuition for our main results are straightforward. First, when governments are pessimistic about the probability a project will be successful, a social impact bond that pays off only when a project is successful will have low ex ante expected financing costs. However, an optimistic private sector will view this bond as a good investment opportunity. Second, when the government is averse to states of the world where the project fails and it must make interest payments associated with the project, it will prefer a financing arrangement that has it make larger payments when the project is successful in exchange for lower payments if the project fails.

Pauly and Swanson (2017) conduct a theoretical analysis of social impact bonds. Like that paper, our paper contains an equivalency result, i.e., debt finance and SIBs are equivalent in a world with perfect information and no risk aversion. However, we differ from Pauly and Swanson in how we break the equivalency. Specifically, they consider models where effort is unobservable and SIBs can incentivize effort. We consider a model where there is asymmetric information about the probability of project success and where governments, because of electoral concerns, are particularly averse to states of the world when they must pay costs associated with a project in excess of benefits.

This equivalency approach links to the theoretical literature on corporate social responsibility (CSR). There, Small and Zivin (2005) argue that firms engaged in CSR and those that are not will be priced the same when firm-provided public goods are substitutes for nonprofit provided services. In contrast, Baron (2008) allows for unobservable effort and consumer and manager affinity for providing public goods and demonstrates that some level 
of CSR is optimal for the firm. However, SIBs differ from CSR. With CSR the firm is providing a public good. With a SIB, a for-profit firm provides financing, but the service is carried out by a not-for-profit entity.

A key mechanism in our model is a desire for governments to avoid states of the world when they must pay costs associated with a project (e.g., financing costs), but receive no benefits from the project (e.g., a failed educational initiative). This mechanism relates to the literature on optimal debt management e.g., (IMF and the World Bank Staff, 2001; Missale, 1997; Filardo et al., 2012; Vajs, 2014), which stresses the need to incorporate long-term debt in country portfolios to avoid the risk of funding crises. While we do not consider projects large enough that failure could lead to a public debt crisis, we show how careful structuring of a SIB can reduce the government's risk exposure.

Interestingly, this approach parallels the static theory of optimal corporate capital structure, e.g., Scott Jr. (1976). In this theory, firms issue equity despite its tax disadvantages (Miller, 1977) to lower the probability of financial distress. ${ }^{4}$ Similarly, to avoid high debt payments in bad states of the world a government would wish to issue equity. However, the government cannot issue ownership shares. SIBs can provide an equity-like instrument that allows interest payments to depend on the state of the world. The benefit of conditioning interest payments on the state of the world is also stressed in the literature on state-contingent sovereign debt, which argues that governments should issue bonds where interest payments depend on the state of the macroeconomy, (IMF and the World Bank Staff, 2017).

Finally, our work relates to the theoretical literature on public-private partnerships: Maskin and Tirole (2008); Iossa and Martimort (2015); Hart (2003); Reich (2000). However, there is a key difference. With a public-private partnership, the government contracts with a for-profit firm to provide a service. With a SIB, typically a nonprofit firm provides the service, and the for-profit firm provides the financing.

The next section provides background on social impact bonds and section provides de-

\footnotetext{
${ }^{4}$ See also Fischer et al. (1989); Hennessy and Whited (2005); Marsh (1982); Stein (1992).
} 
scriptive statistics. Section 4 describes the main model of the paper. Section 5 derives and discusses our key insights about SIBs. Section 6 concludes.

\section{Background on Social Impact Bonds}

A social impact bond is "a multi-stakeholder partnership in which private investors, philanthropic funders and impact investors - not governments - take on the financial risk of expanding preventive programs that help poor and vulnerable people" (Callanan et al., 2012). All SIBs require four core agents to function: the issuer, investors, service providers, and a third-party assessor. The issuer is the entity that issues the SIB. The issuer is most often a public entity, i.e., the government, so much so that hereafter we will use "issuer" and "government" interchangeably. In traditional public financing of social programs, the government provides up-front funding to service providers and shoulders the financial risk associated with the funded program. Under a SIB arrangement, private investors provide the up-front capital and the government agrees to repay them for the program's cost (plus an agreed-upon rate of return) if the program achieves predefined outcomes. This allows the government to (1) pay only for successful programs, (2) pay with a portion of the realized benefits from the program (e.g., cost savings), and (3) align payment with the realization of benefits. Private investors provide up-front funding for the administration, execution, and evaluation of the program. Investors accept the risks associated with program failure in exchange for a commensurately higher rate of return than that of traditional public debt. Private investors could include impact investors (both small- and large-scale) and philanthropic individuals or organizations. ${ }^{5}$

\footnotetext{
${ }^{5}$ See, among others, Gustafsson-Wright et al. (2015); Lower-Basch (2014) for descriptions of the functioning of SIBs.
} 


\section{$2.1 \quad$ Examples}

\subsubsection{Peterborough Recidivism Impact Bond}

The world's first social impact bond, the Peterborough Recidivism Impact Bond, was pioneered in the UK in 2010 as part of an effort by the Ministry of Justice to reduce re-conviction rates among nonviolent offenders (Disley et al., 2015). The bond funded work by the One Service to operate at Peterborough Prison and provide three cohorts of 1,000 male prisoners with pre- and post-release support in housing, training and employment, parenting, substance abuse, and mental health. Social Finance, a nonprofit organization, acted as the intermediary to coordinate the project and raised capital from a total of 17 investors (principally charitable trusts and foundations) who would receive outcome payments if re-conviction rates fell by an average of $7.5 \%$ or more across the targeted cohorts.

The Peterborough Impact bond was highly successful on several fronts. First, re-conviction rates fell by an average of $9 \%$ across the cohorts, triggering repayment in full for all investors plus a return of $3 \%$ interest per annum. ${ }^{6}$ Second, the program led to sustained, ongoing services that continued to operate at Peterborough after the end of the pilot. Third, assessments of the program reported that the service provider found that the SIB funding, with its focus on outcomes-based payments, allowed it more ability to alter services to achieve the stated objectives and respond to feedback from program monitors.

\subsubsection{The ABLE Project for Incarcerated Youth}

The ABLE Project for Incarcerated Youth was established in 2013 with the goal of reducing recidivism among incarcerated youth at Riker's Island jail and has been described by Olson et al. (2013); MDRC (2015). At the program's inception, almost 50\% of 18-year-old men released from Riker's returned to jail within two years. The intervention provided young men

\footnotetext{
${ }^{6}$ Originally intended to operate until 2017, the Peterborough Impact Bond was ended early in 2015 to avoid any duplication in services after roll-out of the nationwide Transforming Rehabilitation program that mandated statutory supervision for short-sentenced offenders. Outcome payments were ultimately based on average recidivism rate reduction across the first two cohorts (9\%).
} 
aged 16 through 21 job training, transitional employment, and job placement services. A successful outcome was defined as a $10 \%$ reduction in the number of days participants were jailed during the subsequent year. Goldman Sachs and Bloomberg Philanthropies invested (USD) 9.6 million to fund the program and could have earned up to (USD) 11.7 million in repayment (22\% rate of return) from the City of New York's Department of Corrections. Preliminary results found no statistically significant reduction in recidivism between those who received the intervention and a matched control group. Therefore, while the program was intended to last four years, it shut down early and investors were not repaid.

\subsubsection{Massachusetts Juvenile Justice Pay for Success Initiative}

As described in Rangan and Chase (2015), the Commonwealth of Massachusetts launched in 2014 the "Massachusetts Juvenile Justice Pay for Success Initiative" to address recidivism among young adults. An estimated $55 \%$ of young adults who are on probation or age out of the juvenile justice system will be imprisoned at least once within three years. The program targets roughly one thousand individuals and aims to reduce re-incarceration rates by $40 \%$ and increase job readiness and employment. Massachusetts partnered with Roca Inc., a nonprofit focused on addressing recidivism, to provide outreach and skill-building interventions. Third Sector Capital Partners acted as the intermediary and raised (USD) 28 million from a host of private investors to cover $85 \%$ of Roca's costs upfront. The project was expected to run for six years and the investors, Goldman Sachs and the Kresge Foundation for Living Cities, will only be repaid if the aforementioned incarceration reduction outcomes are achieved, at an interest rate of 3-5\% depending on the investor. Incarcerating one inmate costs approximately (USD) 55,000 per annum, so reducing prison populations through social programs could lead to significant savings for Massachusetts taxpayers. Reducing incarceration by $40 \%$ is estimated to generate (USD) 22 million in budgetary savings, and a $55 \%$ reduction would yield (USD) 33 million in savings. ${ }^{7}$

\footnotetext{
${ }^{7}$ For more information on this SIB see https://www.thirdsectorcap.org/portfolio/massachusetts-juvenilejustice-pfs-initiative/ .
} 


\subsubsection{Additional Examples}

While prison recidivism has been a popular issue area for social impact bonds, over the past decade these mechanisms have been used in a wide array of other contexts that highlight their versatility and customizability. ${ }^{8}$ For example, the Educate Girls Development Impact Bond, operating in Rajasthan, India, aimed to address issues of educational access and attendance among schoolgirls. Payments for the Educate Girls bond were structured around two performance measures: learning levels and enrollment rates. The program achieved $160 \%$ of its target learning outcomes and threshold investors were repaid their principal investments in full and received an impressive $15 \%$ return, which is set to be reinvested in future development programs. ${ }^{9}$

Another social impact bond, issued in Cameroon in 2017, focuses on ophthalmic health. ${ }^{10}$ The Cameroon Cataract Development Bond is a financing vehicle to fund as many as 18,000 cataract surgeries over five years. This bond structures its payment thresholds around three outcome categories: volume of completed surgeries, quality of completed surgeries, and financial sustainability of the surgical hospital. Scheduled to conclude in 2023, it is currently on target to meet all three outcomes goals, and the highest potential return to investors is $8 \%$.

\section{Data and Descriptive Statistics}

\subsection{Data Description}

We obtain data from the Social Impact Bond Global Database as compiled and maintained by Social Finance. ${ }^{11}$ This data set is regularly updated and intended to include all issued

\footnotetext{
${ }^{8}$ Responding to the COVID-19 threat, Palandjian and Brest (2020) argue they are a useful mechanism to finance pandemic response.

${ }^{9}$ Results for the Educate Girl's SIB are obtained from UBS Optimus Foundation (2018) available at: https://instiglio.org/educategirlsdib/about-the-dib/ .

${ }^{10}$ Oroxom et al. (2018) provide a detailed description of the Cameroon bond. Their paper is available at: https://golab.bsg.ox.ac.uk/knowledge-bank/case-studies/cameroon-cataract-bond/ .

${ }^{11}$ The data are available at: https://sibdatabase.socialfinance.org.uk/ .
} 
SIBs. We have data for 131 projects on the following variables for each SIB project: target population, location, launch date, duration of bond, capital raised, maximum outcome payments, investors, outcomes funder, service provider, and intermediary (if applicable). In constructing the dataset for this paper, we convert all local currencies to USD and include a variable categorizing each SIB location country by its World Bank income classification.

While the Social Finance database includes information on metrics and outcomes when this information is publicly available, key data are missing for many SIB projects in our database. For example, 30 projects have undisclosed values for capital raised and 24 projects have unspecified investor counts. Of all the projects, only six completed projects have a published return on investment. ${ }^{12}$

\subsection{Descriptive Statistics}

Table 1 provides descriptive statistics for completed and ongoing social impact bond projects. The vast majority (95\%) of SIB projects are located in high-income countries, with the highest concentration in Europe and Central Asia (56\%) followed by North America (23\%) and East Asia and the Pacific (12\%) (Table 1). Only three SIB projects have been located in Latin America (Peru, Argentina, and Colombia), four in Sub-Saharan African (South Africa, Cameroon, Uganda, Kenya, the Congo, Mali, and Nigeria), two in the Middle East (both in Israel), and three in South Asia (all in India). These projects cover a broad set of issue areas, from affordable housing programs to medical procedures to sanitation infrastructure to wildlife conservation programs. Most projects, however, fall under the umbrellas of workforce development, child and family welfare, or housing and homelessness. One possible explanation for such concentration in these issue areas is that they often involve shorter-term intervention programs. Programs with shorter durations may lend themselves to earlier evaluation and faster repayment for investors.

Following their initial launch with the Peterborough Impact Bond in 2010, new social

\footnotetext{
${ }^{12}$ We are in the process of updating the data based on other publicly available information for each project. This work is ongoing and will be used to supplement the Social Finance database.
} 
Table 1: Social Impact Bond Project Distribution by Issue Area, Country Income Classification, and Region

\begin{tabular}{lrr}
\hline Project Characteristic & Count & Percent \\
\hline Issue Area & & \\
\hline Workforce Development & 41 & $31 \%$ \\
Child and Family Welfare & 20 & $15 \%$ \\
Housing/Homelessness & 22 & $17 \%$ \\
Health & 22 & $17 \%$ \\
Criminal Justice & 12 & $9 \%$ \\
Education and Early Years & 11 & $8 \%$ \\
Poverty and Environment & 3 & $2 \%$ \\
\hline Country Income Classification & & \\
\hline High income & 122 & $95 \%$ \\
Upper middle income & 3 & $2 \%$ \\
Lower middle income & 4 & $3 \%$ \\
Low income & 0 & $0 \%$ \\
\hline Region & & \\
\hline Europe and Central Asia & 73 & $56 \%$ \\
North America & 30 & $23 \%$ \\
East Asia and Pacific & 16 & $12 \%$ \\
Sub-Saharan Africa & 4 & $3 \%$ \\
Latin America and the Caribbean & 3 & $2 \%$ \\
South Asia & 3 & $2 \%$ \\
Middle East and North Africa & 2 & $2 \%$ \\
\hline
\end{tabular}

Source: Authors' calculations based on the Social Finance Impact Bond Global Database. This table excludes two projects undertaken in multiple countries of different income classifications, including work in one low-income country, Uganda, which is not reflected in the above aggregation. 
impact bond projects began gaining traction. The number of new bonds peaked in 2017, with 51 launching in that year alone. 2018 saw a drop to 11 new bonds - the lowest since 2014. Additionally, 2019 launches to date appear consistent with this decline. Whether the drop in recent years will be indicative of future trends in the creation of new SIB is unclear. The first health-focused SIB launched in 2015. Health became an increasingly popular issue area for SIBs over the next two years, increasing from two new launches in 2015 to 12 in 2017. Though the number of launches, including health-focused launches, declined sharply in 2018, health-focused launches comprised $27 \%$ of all new SIBs - the highest percentage to date.

Figure 1: SIB Projects by Launch Year and Issue Area (2010 - 2019)

Source: Authors' calculations based on Social Finance Impact Bond Global Database.

Total investment in social impact bonds has increased almost every year since their inception in 2010 with the Peterborough Impact Bond (in 2011 there were no new bonds). 2012-2017 saw steady increases in total investment, with new investment peaking in 2016. Although the growth rate of investment levels has slowed in recent years, total global investment in SIBs is the highest it has ever been at 403 million USD. Total global investment is 1.5 times higher than it was in 2016 when new investment peaked. 
Figure 2: Global SIB Investment Level (2010-2019)

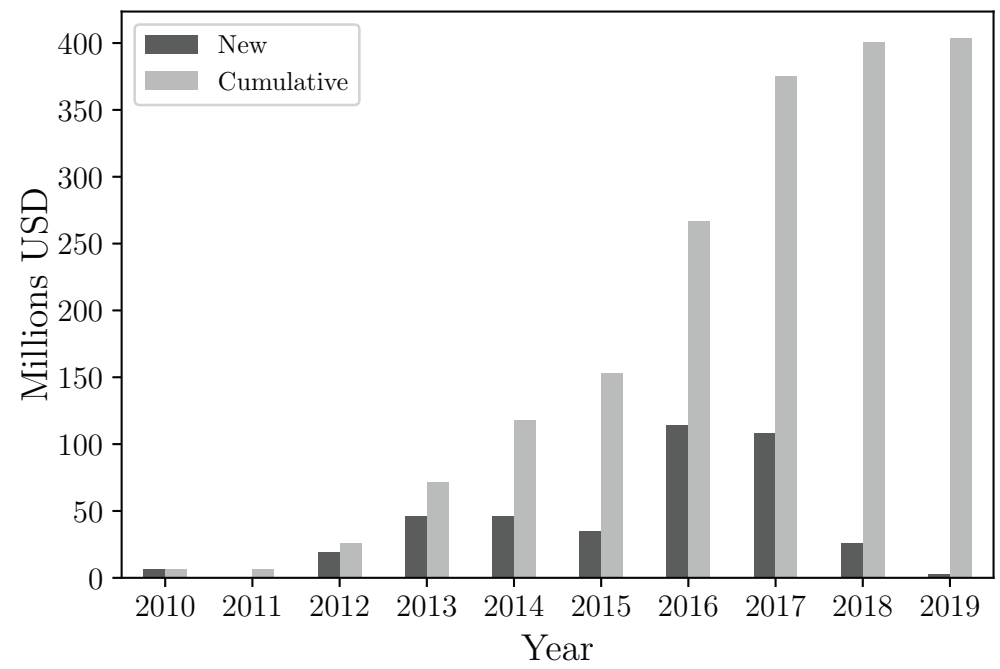

Source: Authors' calculations based on data from Social Finance Impact Bond Global Database. Collection for 2019 is ongoing; amount shown does not yet fully reflect to-date 2019 investment levels.

Table 2 provides summary statistics for some of the key variables in the data set. The average investment in a social impact bond is (USD) 3.8 million, although the largest project involved a (USD) 30 million dollar investment and the smallest (USD) 100,000. Projects tend to have larger investment values in the US than they have in the UK or globally. Outcome payments average about (USD) 6 million but clearly vary by project. A typical project has multiple investors, with the average number of investors being three. Finally, average maturity of these bonds is 4.5 years, although the maturity is longer in the US at roughly 6.5 years. 
Table 2: SIB Project Investment Data by Country $(2010-2019)$

\begin{tabular}{ccccc}
\hline Country & $\begin{array}{c}\text { Capital Raised } \\
\text { (USD Millions) }\end{array}$ & $\begin{array}{c}\text { Max Outcomes } \\
\text { Payments } \\
\text { (USD Millions) }\end{array}$ & $\begin{array}{c}\text { Number of } \\
\text { Investors }\end{array}$ & $\begin{array}{c}\text { Time to Maturity } \\
\text { (Years) }\end{array}$ \\
\hline UK & 1.64 & 3.59 & 3 & 3.97 \\
US & {$[0.37-6.10]$} & {$[0.10-12.2]$} & {$[1-17]$} & {$[2-10]$} \\
Other & 8.77 & 9.95 & 5 & 6.56 \\
Global & {$[0.15-30]$} & {$[0.15-34]$} & {$[1-40]$} & {$[3-30]$} \\
& 2.9 & {$[0.23-15.81]$} & {$[1-59]$} & 4.3 \\
& {$[0.11-27]$} & 5.85 & 3 & $10]$ \\
& {$[0.1-30]$} & {$[0.1-34.5]$} & {$[1-17]$} & {$[1-10]$}
\end{tabular}

Source: Authors' calculations based on data from the Social Finance Impact Bond Global Database. Average values listed, min and max in brackets.

\section{Model}

This section sets forth our model of social impact bonds. It first describes a project the government could potentially finance. Next, it describes the objectives of the government and the investor who may finance the project. Then we define the financing instruments: a debt contract and a SIB. Finally, we describe the incentive compatibility conditions that are required for the government to provide payment and the investor to provide financing sufficient to implement the project.

\subsection{Project}

Consider a situation where the government is deciding to finance a public project. The project $\operatorname{costs} c$, this period, to implement and has a potential benefit of $b$ next period. Next period there are two possible states of the world: the good state and the bad state. In the good state the government receives the benefit $b$; in the bad state the government receives zero. The good state of the world occurs with unknown probability denoted by $p^{*}$. Figure 3 summarizes the project. 
Figure 3: Potential Project

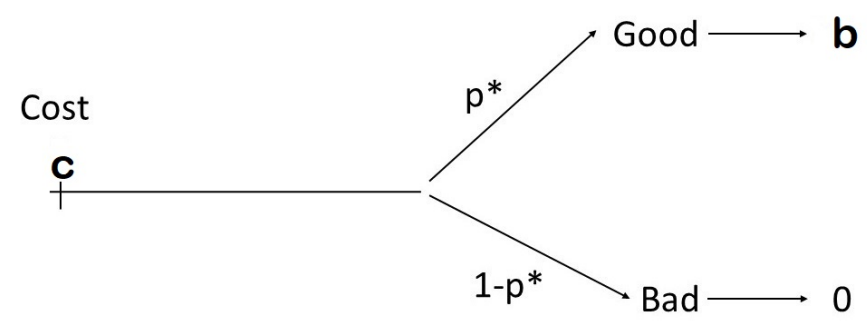

Time 1

Time 2

\section{$4.2 \quad$ Financing}

There are two possible mechanisms to finance the project. The first, debt finance, constrains the government's payments to be constant across the two states. The second, a social impact bond, allows the payments to be conditional on the benefits the government receives and therefore on the state of the world.

\subsection{Agents}

The model contains two types of agents: a risk-neutral investor and the government. The risk-neutral investor will only invest in a project if she expects to get a return greater than or equal to her required return. Her required return is given by

$$
r-\omega
$$

Here $r$ is the expected return on comparable government debt and $\omega$ represents the discount an investor is willing to take to invest in a socially responsible project. The investor also believes that the project will succeed with probability $p$, which may or may not equal $p^{*}$ (the true probability).

The second type of agent is the government. The government maximizes the expected present value of benefits minus costs from implementing the project. However, the government has an added preference for avoiding unfunded costs. It is specifically averse to 
experiencing states of the world when it must pay costs associated with a project (e.g., debt payments) when no corresponding benefits materialize. While we do not currently model why this is the case, one potential explanation is that failed projects can be portrayed as wasteful spending by political opponents, reducing a politician's reelection probability. The magnitude of this aversion is captured with the parameter $\phi .^{13}$

Subsequently, the government's expected utility is given by

$E(U)=-(1+\phi) c_{1}+\frac{1}{1+r}\left[q\left(b-c_{2}^{g}\right)-(1-q) c_{2}^{b}\right]-\frac{\phi}{1+r}\left[q * \max \left(0, c_{2}^{g}-b\right)+(1-q) * \max \left(0, c_{2}^{b}\right)\right]$

In this function $c_{1}$ are any costs the government pays in the first period, $c_{2}^{g}$ are costs the government pays in the second period if the good state of the world occurs, $c_{2}^{b}$ are costs the government pays in the second period if the bad state of the world occurs, $\frac{1}{1+r}$ is the government's discount factor, and $q$ is the government's belief regarding the probability that the good state of the world will occur. As with the investor, this probability $q$ may not necessarily equal the true probability $p^{*}$. Finally, note that when the government chooses not to finance the project, its utility equals zero.

To grasp this utility function, note that the first term captures government costs in the first period. The cost, $c_{1}$, is multiplied by $1+\phi$ because there are no benefits in the first period to offset any costs and therefore, given the government's aversion to unfunded costs, government utility falls by an additional factor $\phi$. The second term represents the expected present discounted value of net benefits from the project. The third term represents the expected present discounted value of unfunded benefits. The use of the max function ensures that when benefits $b$ exceed costs in the good state of the world, $c_{2}^{g}$, the unfunded cost is exactly zero.

\footnotetext{
${ }^{13}$ For example, Rogoff and Sibert (1988) consider a model where politicians have unobserved competency. Spending money with little benefit reveals the politician's incompetency and results in her being voted out of office.
} 


\subsection{Financial Instruments}

Two instruments are available to finance the project: traditional debt finance and a social impact bond.

Definition 1. Debt finance is a contract that requires the government to pay the investor $c(1+i)$ in each state of the world. $i$ is the interest rate on the debt contract.

Definition 2. A social impact bond (SIB) is a contract that requires the government to pay the investor prespecified values $c_{2}^{g} \geq 0$ in the good state of the world and $c_{2}^{b} \geq 0$ in the bad state of the world. Additionally, consistent with the SIBs we observe in the data, we require that $c_{2}^{g} \geq c_{2}^{b}$.

\subsection{Incentive Compatibility}

A project is government incentive compatible if the government would choose to implement the project with an available financing instrument. The project is investor incentive compatible if the investor is willing to provide financing for the project. For the investor, incentive compatibility requires that her expected return be greater than the required return given by equation (1). For the government, incentive compatibility requires that the expected utility of implementing the project is greater than the utility of not implementing the project, 0 .

Definition 3. A project is implementable if it is incentive compatible for both the investor and the government.

\section{Results}

This section examines the conditions under which the government can implement potential projects with debt finance and the conditions under which a social impact bond can expand the set of projects that can be financed. 


\subsection{Debt Finance}

Theorem 1. A debt contract with interest rate $i$ can implement the project if and only if $\frac{q b}{c[1+\phi(1-q)]}-1 \geq r-\omega$.

Proof. See appendix.

To understand this result, note that the condition requires that the government's expected return on the project be greater than the required return of the investor. However, note that the expected cost of the project to the government is not just $c$ but $c[1+\phi(1-q)]$. This is the government's real cost because, based on its beliefs, with probability $1-q$ the government will have to make debt payments in excess of received benefits, which has an additional cost of $\phi$ per dollar of unfunded costs. However, when the expected benefit of the project is high enough to cover the government's interest costs while accounting for its aversion to unfunded costs, the government is willing to finance the project with debt.

Remark 1. When the government has no preference for avoiding states of the world with unfunded costs, i.e., $\phi=0$, then any project where $\frac{q b}{c}-1 \geq r-\omega$ can be implemented. This result is the conventional result that the government will finance any project for which the expected return is greater than the rate at which it can borrow.

Remark 2. When $\frac{q b}{c[1+\phi(1-q)]}-1>r-\omega$, the project is implementable with any interest rate $i$ where $\frac{q b}{c[1+\phi(1-q)]}-1>i>r-\omega$. The higher the interest rate, the larger is the share of the expected benefit from the project that is paid out to the investor.

\subsection{Social Impact Bond}

Now we consider the set of projects that can be implemented under a social impact bond, and specifically the capacity of a SIB to expand the set of implementable projects.

Theorem 2. A social impact bond is investor incentive compatible if and only if $\frac{p c_{2}^{g}+(1-p) c_{2}^{b}}{c}-$ $1>r-\omega$ and is government incentive compatible if and only if $\frac{q b}{c}>\frac{q c_{2}^{g}+(1-q)(1+\phi) c_{2}^{b}}{c}$. 
Proof. See appendix.

Theorem 3. A project is implementable using a social impact bond whenever $p \frac{b}{c}>(r-\omega+1)$. Moreover if $p \geq q$, this condition will hold for any project that is implementable with a social impact bond.

Proof. See appendix

To develop some intuition for this last result, note that if the investor believes the good state of the world will occur with probability $p$, the left-hand side of this condition is the expected return on the contract that pays all the project benefits to the investor in the good state and pays zero in the bad state. The government would accept that contract because it would set government utility to exactly zero. Therefore, whenever this condition holds we can implement the project.

To understand why when $p \geq q$ this condition must hold for any implementable project, consider the contract $c_{2}^{g}=\frac{c(r-\omega+1)}{p}$ and $c_{2}^{b}=0$. This contract has the benefit of completely eliminating unfunded costs and exactly compensating the investor by giving her exactly the required return. Moreover, when $p \geq q$ the investor values payments in the good state relatively more than the government because the investor views these states as more likely. As such it is best for the government to transfer all its payments to the good state. Therefore, from the government's point of view this is the best contract, and if it cannot implement the social impact bond no other contract will. Now note that the government would accept this contract if it gives a positive expected return to the government. The government will get a positive expected return if $q\left(b-\frac{c(r-\omega+1)}{p}\right)>0$, which leads to the condition of theorem 3 .

An important implication of theorem 3 is that when at least one investor is as optimistic as the government, then any project with positive expected value from the point of view of the government can be implemented.

With only debt finance, theorem 1 demonstrates that only projects where the expected return $\frac{q b}{c} \geq(1+r-\omega) *[1+\phi(1-q)]$ will be implementable. We can think about the 
government's aversion to unfunded costs as creating a wedge between the expected return on a project and the cost of debt finance. The size of the wedge is proportional to $\phi$, the magnitude of the government's aversion to unfunded costs, and to $1-q$, the probability that the government experiences unfunded costs.

Because a social impact bond can eliminate these unfunded costs, if the government can find an investor that is at least as optimistic as it is, it can fund any project with an expected value greater than the interest cost of debt, i.e., $\frac{q b}{c} \geq(1+r-\omega)$ because the investor has a success belief $p$ where $\frac{p b}{c} \geq(1+r-\omega)$. As such, the SIB provides a solution to the inefficiency caused by the government's aversion to unfunded costs. In fact, if the inefficiency is large enough (for example if $\phi$ is large) a SIB could implement a project that debt finance cannot, even if the private sector is more pessimistic than the government.

Remark 3. When $\phi=0$ and $p \leq q$ any project that is implementable with a SIB is also implementable with debt finance.

Proof. Setting $\phi=0$ in theorem 2 we obtain that a social impact bond is government incentive compatible only if $q \frac{b}{c}>\frac{q c_{2}^{g}+(1-q) c_{2}^{b}}{c}$. Recall, also from theorem 2 , that the SIB is only investor incentive compatible if $\frac{p c_{2}^{g}+(1-p) c_{2}^{b}}{c}-1>r-\omega$. When $q \geq p$ these two conditions imply $\frac{q b}{c}-1 \geq r-\omega$, which is the implementability condition from theorem 1 for debt finance.

Remark 3 implies that for social impact bonds to add value by increasing the set of implementable projects, we must either have investors who are more optimistic than the government or have a government that is averse to unfunded costs.

\subsection{Examples}

Figure 4 presents a specific example to illustrate the role that government and investor beliefs play in the implementability of the project. We parameterize this example using an aversion to unfunded $\operatorname{costs} \phi=0$, a benefit-cost ratio $\frac{b}{c}=1.4$, and the investor's required return 
$r-\omega=0.08$. The y-axis gives the investor's belief for the probability that the project will succeed. The x-axis gives the government's probability belief that the project will succeed. The upper-right square, labeled BOTH, indicates that for projects where the government and investors are very optimistic about project success both debt and a SIB can implement the project. Now moving to the rectangle in the upper left of the diagram, we have the region where only the SIB can implement the project. In this region the government is unwilling to finance the project with debt because the government believes that the project is likely enough to fail that it is not worth financing at the $8 \%$ interest rate. However, as long as the investor is sufficiently optimistic, a SIB can implement the project. Because the investor thinks the project is likely to succeed, the SIB meets her required return. On the other hand, because the government is more pessimistic about the project, its expected cost is less than the investor's required return. Finally, note that debt implementability is insensitive to the investor's belief about project success. This results occurs because debt guarantees the investor the same payment no matter the state of the world. 
Figure 4: Disagreement about the Probability of Success

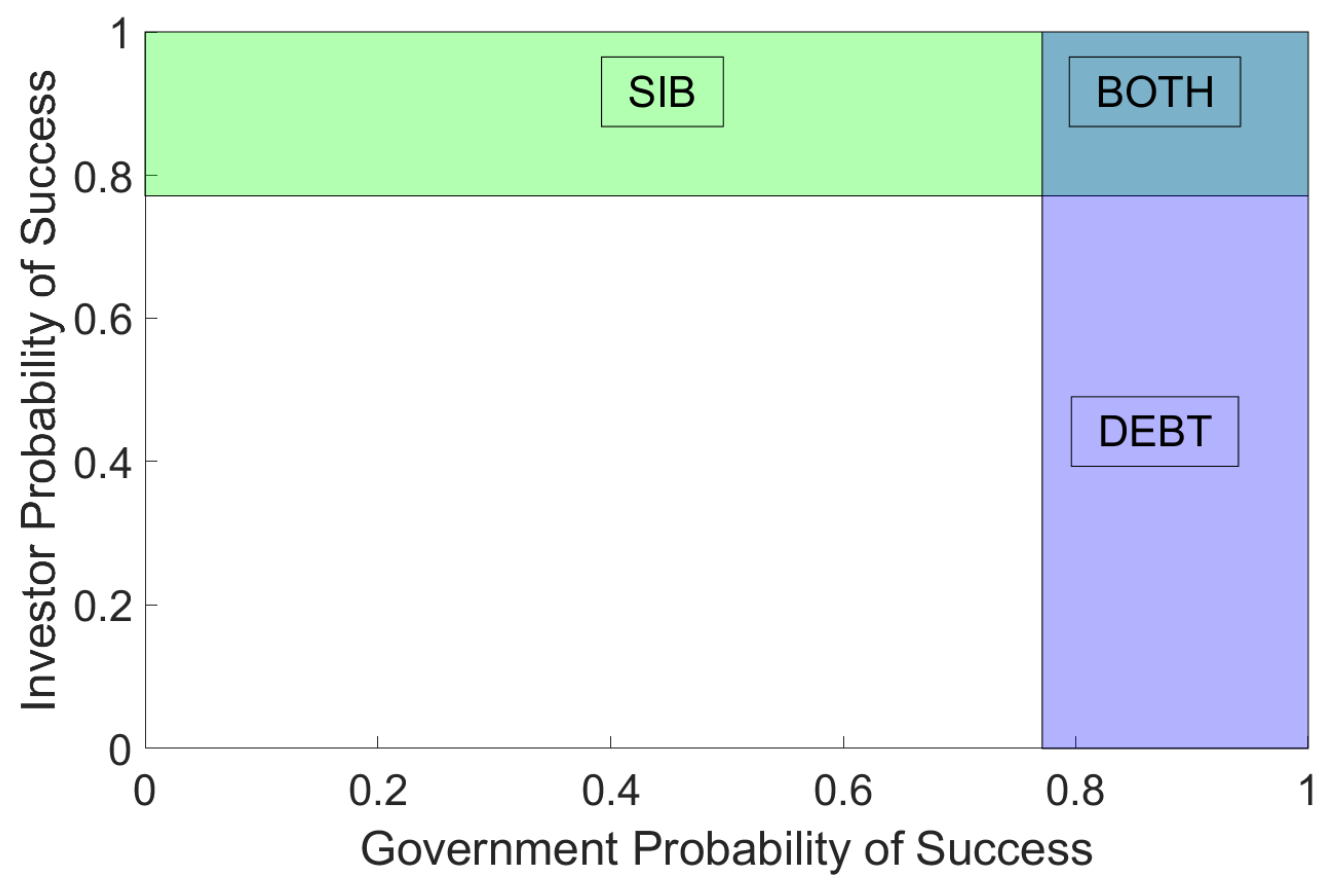

Note: This figure indicates the range of investor and government subjective probabilities of project success where the project can be implemented with debt, a social impact bond (SIB) or both. The parameters used are $\phi=0, \frac{b}{c}=1.4, r-\omega=0.08$.

Next, figure 5 uses a similar example to illustrate the role that aversion to unfunded costs has on the implementability of the project. Again, the benefit-cost ratio $\frac{b}{c}=1.4$, and an investor's required return $r-\omega=0.08$. In this figure, we set the investor's probability of success $(p)$ equal to the government's probability of success $(q)$ and consider a range of values for the aversion to unfunded costs $(\phi)$ from zero to three. Any project for which the investor and the government are sufficiently optimistic can be implemented by a social impact bond. For SIBs, the aversion to unfunded costs is irrelevant because the SIB does not require the government to make payments in the bad state (when unfunded costs could occur). However, as the aversion to unfunded costs rise, fewer and fewer projects can be implemented with debt finance. Because the government risks unfunded costs, it will only be willing to debt finance projects for which it is highly optimistic. 
Figure 5: The Effect of Unfunded Costs

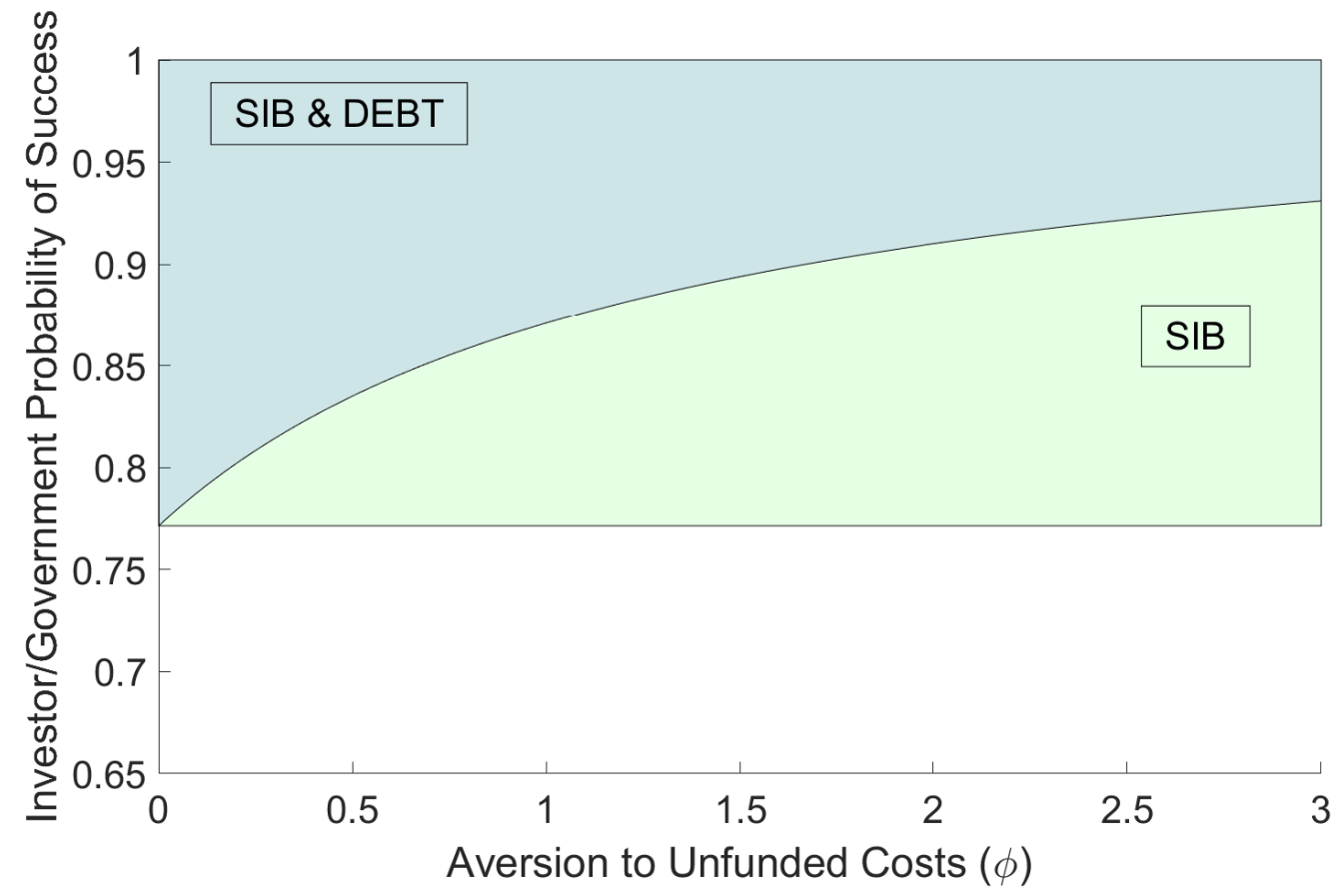

Note: This figure indicates the range of $\phi$ (aversion to unfunded costs) where the project can be implemented with debt, a social impact bond (SIB) or both, given the government and the investor's belief that the project succeeds. Here we assume that the government and investor share the same belief. The parameters used are $\frac{b}{c}=1.4, r-\omega=0.08$.

\section{Conclusion}

In this paper we formulate a novel theory of social impact bonds. Social impact bonds allow the government to finance positive net present value projects that cannot be financed with traditional debt finance. SIBs solve two inefficiencies. The first inefficiency arises when the government is unduly pessimistic about the possible success of the project. The second inefficiency arises when political realities lead politicians to be overly concerned about paying for underperforming projects. By allowing the payouts to depend on the project's success and the beliefs of the investor, the SIB can enable the financing of positive net present value projects when one or both of these inefficiencies prevent the project from being financed through traditional debt finance. As both these features are common in public investment, SIBs represent a useful innovation in public finance and should be considered when traditional 
debt financing has been rejected.

Looking forward, additional features of SIBs are worthy of exploration. One such feature is the role an investor can play in affecting the probability a project succeeds. Another important issue to explore is the SIB transaction cost relative to traditional debt finance and the resulting appropriate scale of social impact bonds. Finally, the implementation of a SIB financed project may alter beliefs about the probable success of the project, enabling the project to be financed by debt finance in the future. A dynamic model would be needed to explore this avenue. 


\section{References}

Matt Aitken, Amy Bogie, Christi Electris, Farzana Hoque, Kristin Lang, and Jaime Silverstein. Report on U.S. sustainable, responsible and impact investing trends. Technical report, US SIF Foundation, 2018.

David P Baron. Managerial contracting and corporate social responsibility. Journal of Public Economics, 92(1-2):268-288, 2008.

Jedrzej Bialkowski and Laura T. Starks. SRI Funds: Investor Demand, Exogenous Shocks and ESG Profiles. Working papers in economics, University of Canterbury, Department of Economics and Finance, 2016.

L Callanan, J Law, and L Mendonca. From Potential to Action: Bringing Social Impact Bonds to the U.S. Technical report, McKinsey \& Company, 2012.

Emma Disley, Chris Giacomantonio, Kristy Kruithof, and Megan Sim. The payment by results social impact bond pilot at HMP Peterborough. 2015.

Andrew Filardo, Madhusudan Mohanty, and Ramon Moreno. Central bank and government debt management: Issues for monetary policy. In Bank for International Settlements, editor, Fiscal policy, public debt and monetary policy in emerging market economies, volume 67 of BIS Papers chapters, pages 51-71. Bank for International Settlements, July 2012.

Edwin O Fischer, Robert Heinkel, and Josef Zechner. Dynamic capital structure choice: Theory and tests. The Journal of Finance, 44(1):19-40, 1989.

Emily Gustafsson-Wright, Sophie Gardiner, and Vidya Putcha. The potential and limitations of impact bonds: Lessons from the first five years of experience worldwide. Technical report, The Brookings Institution, 2015.

Oliver Hart. Incomplete contracts and public ownership: Remarks, and an application to public-private partnerships. The Economic Journal, 113(486):C69-C76, 2003.

Christopher A Hennessy and Toni M Whited. Debt dynamics. The Journal of Finance, 60 (3):1129-1165, 2005.

IMF and the World Bank Staff. Guidelines for public debt management. Technical report, The International Monetary Fund and the World Bank, Washington, D.C., 2001.

IMF and the World Bank Staff. State-contingent debt instruments for soverigns. Technical report, The International Monetary Fund and the World Bank, Washington, D.C., 2017.

Elisabetta Iossa and David Martimort. The simple microeconomics of public-private partnerships. Journal of Public Economic Theory, 17(1):4-48, 2015.

Elizabeth Lower-Basch. Social impact bonds: Overview and considerations. Center for Law and Social Policy, 7, March 2014.

Paul Marsh. The choice between equity and debt: An empirical study. The Journal of Finance, 37(1):121-144, 1982.

Eric Maskin and Jean Tirole. Public-private partnerships and government spending limits. International Journal of Industrial Organization, 26(2):412-420, 2008.

MDRC. MDRC Statement on the Vera Institute's Study of the Adolescent Behavioral Learning Experience (ABLE) Program at Rikers Island, 2015. URL wWw. mdrc.org/news/announcement/mdrc-statement-vera-institute-s-studyadolescent-behavioral-learning-experience.

Merton H Miller. Debt and taxes. The Journal of Finance, 32(2):261-275, 1977. 
Alessandro Missale. Managing the public debt: the optimal taxation approach. Journal of Economic Surveys, 11(3):235-265, September 1997.

John Olson, Andrea Phillips, et al. Rikers Island: the first social impact bond in the United States. Community Development Investment Review, (01):097-101, 2013.

Roxanne Oroxom, Amanda Glassman, and Lachlan McDonald. Structuring and Funding Development Impact Bonds for Health: Nine Lessons from Cameroon and Beyond. 2018.

Tracy Palandjian and Paul Brest. After the pandemic: Addressing the permanent crisis with pay for success programs. Stanford Social Innovation Review, March 2020.

Mark V. Pauly and Ashley Swanson. Social impact bonds: New product or new package? The Journal of Law, Economics, and Organization, 33(4):718-760, Nov. 2017.

V. Kasturi Rangan and Lisa A. Chase. Massachusetts pay-for-success contracts: Reducing juvenile and young adult recidivism. Harvard Business School Publishing, 2015. HBS Case No. 9514061.

Michael R Reich. Public-private partnerships for public health. Nature Medicine, 6(6):617, 2000.

Luc Renneboog, Jenke ter Horst, and Chendi Zhang. Socially responsible investments: Institutional aspects, performance, and investor behavior. Journal of Banking and Finance, 32(9):1723-1742, 2008.

Kenneth Rogoff and Anne Sibert. Elections and Macroeconomic Policy Cycles. The Review of Economic Studies, 55(1):1-16, 011988.

James H Scott Jr. A theory of optimal capital structure. The Bell Journal of Economics, 7 (1):33-54, 1976 .

Arthur A Small and Joshua Graff Zivin. A Modigliani-Miller theory of altruistic corporate social responsibility. Topics in Economic Analysis \& Policy, 5(1), 2005.

Social Finance. Impact bond global data base, 2019. URL https://sibdatabase.socialfinance.org.uk.

Jeremy C Stein. Convertible bonds as backdoor equity financing. Journal of Financial Economics, 32(1):3-21, 1992.

UBS Optimus Foundation. Knowledge is power: The world's first development impact bond in education. Technical report, UBS, Zurich, Switzerland, 2018.

Stephen Vajs. Government debt issuance: issues for central banks. In Bank for International Settlements, editor, The role of central banks in macroeconomic and financial stability, volume 76, pages 29-46. Basel, Switzerland, 2014. 


\section{Appendix: Proofs of Theorems}

Theorem 1. A debt contract with interest rate $i$ can implement the project if and only if $\frac{q b}{c[1+\phi(1-q)]}-1 \geq r-\omega$.

Proof. If a project is incentive compatible for the government it must be true that $b>c_{2}^{g}$, otherwise every term in the government's utility would be negative. Given that $b>c_{2}^{g}$, the government's expected utility is given by $\frac{1}{1+r}\left[q\left(b-c_{2}^{g}\right)-(1-q) c_{2}^{b}\right]-\frac{\phi}{1+r}\left[(1-q) c_{2}^{b}\right]$. Substituting in $c(1+i)=c_{2}^{g}=c_{2}^{b}$, we have that the government's expected utility equals $\frac{1}{1+r}[b-c(1+i)]-\frac{\phi}{1+r}[(1-q) c(1+i)]$, which is greater than zero if and only if $\frac{b}{c[1+\phi(1-q)]}-$ $1 \geq i$. Because the project is incentive compatible for the investor if and only if $i \geq r-\omega$, the project is implementable if and only if $\frac{b}{c[1+\phi(1-q)]}-1 \geq r-\omega$.

Theorem 2. A social impact bond is investor incentive compatible if and only if $\frac{p c_{2}^{g}+(1-p) c_{2}^{b}}{c}-$ $1>r-\omega$ and is government incentive compatible if and only if $q \frac{b}{c}>\frac{q c_{2}^{g}+(1-q)(1+\phi) c_{2}^{b}}{c}$.

Proof. Because the social impact bond pays the investor $c_{2}^{g}$ in the good state and $c_{2}^{b}$ in the bad state of the world, and the investor believes the good state will occur with probability $p$, then her expected return is equal to $\frac{p c_{2}^{g}+(1-p) c_{2}^{b}}{c}$ for the initial investment of $c$. This is greater than the required return if and only if $\frac{p c_{2}^{g}+(1-p) c_{2}^{b}}{c}>1+r-\omega$.

If a project is incentive compatible for the government it must be true that $b>c_{2}^{g}$, otherwise every term in the governments utility would be negative. Given that $b>c_{2}^{g}$, the government's expected utility is given by $\frac{1}{1+r}\left[q\left(b-c_{2}^{g}\right)-(1-q) c_{2}^{b}\right]-\frac{\phi}{1+r}\left[(1-q) c_{2}^{b}\right]$. Utility is nonnegative when $q b-q c_{2}^{g}-(1-q) c_{2}^{b}-\phi(1-q) c_{2}^{b}>0$. Rearranging we get $q \frac{b}{c}>\frac{q c_{2}^{g}+(1-q)(1+\phi) c_{2}^{b}}{c}$.

Theorem 3. A project is implementable using a social impact bond whenever $p \frac{b}{c}>(r-\omega+1)$. Moreover if $p \geq q$, this condition will hold for any project that is implementable with a social impact bond.

Proof. Based on the previous theorem, a project is government incentive compatible if and only if $q_{c}^{b}>\frac{q c_{2}^{g}+(1-q)(1+\phi) c_{2}^{b}}{c}$. To find the maximum set of projects that will satisfy this condi- 
tion we consider the social impact bond contract that makes the investor indifferent between investing and not investing in the SIB, i.e., her incentive compatibility constraint holds as an equality. Therefore, $p c_{2}^{g^{*}}+(1-p) c_{2}^{b^{*}}=c(r-\omega+1)$, which implies $c_{2}^{b^{*}}=\frac{c(r-\omega+1)-p c_{2}^{g^{*}}}{1-p}$. From the previous theorem, this contract is incentive compatible for the government if and only if $q \frac{b}{c}>q \frac{c_{2}^{g^{*}}}{c}+\frac{(1-q)(1+\phi)}{c}\left[\frac{c(r-\omega+1)-p c_{2}^{g^{*}}}{1-p}\right]$ or $q \frac{b}{c}>\left[q-\frac{p(1-q)(1+\phi)}{1-p}\right] \frac{c_{2}^{g^{*}}}{c}+\frac{(1-q)(1+\phi)}{1-p}(r-\omega+1)$.

Consider the contract $c_{2}^{g^{*}}=\frac{c(r-\omega+1)}{p}$ and $c_{2}^{b^{*}}=0$. For this contract the government's implementability constraint simplifies to $q \frac{b}{c}>q \frac{c(r-\omega+1)}{p}$ or $p \frac{b}{c}>(r-\omega+1)$. Therefore, when this condition holds there is a social impact bond that is able to implement the project.

Additionally when $p \geq q$, the first term on the right-hand side of the government's incentive compatibility condition $\left[q-\frac{p(1-q)(1+\phi)}{1-p}\right] \frac{c_{2}^{g^{*}}}{c}$ is negative. Because we will maximize the set of implementable projects by making the right-hand side of the government's compatibility constraint as small as possible, we can maximize the set of implementable projects with $c_{2}^{g^{*}}=\frac{c(r-\omega+1)}{p}$ and $c_{2}^{b^{*}}=0$. In this case the implementability constraint simplifies to $q \frac{b}{c}>q \frac{c(r-\omega+1)}{p}$ or $p \frac{b}{c}>(r-\omega+1)$. Moreover, our contract that implements the social impact bond maximizes the set of implementable projects. Therefore this condition describes all implementable projects. 